\title{
Taking sociology seriously: a new approach to the bioethical problems of infectious disease Mark Tausig ${ }^{1}$, Michael J. Selgelid ${ }^{2}$, Sree Subedi ${ }^{3}$ and Janardan Subedi ${ }^{3}$
}

\author{
${ }^{1}$ Department of Sociology, University of Akron \\ ${ }^{2}$ Centre for Applied Philosophy and Public Ethics and Menzies Centre for \\ Health Policy, The Australian National University \\ ${ }^{3}$ Department of Sociology and Gerontology, Miami University
}

\begin{abstract}
After a history of neglect, bioethicists have recently turned their attention to the topic of infectious disease. In this paper we link bioethicists' earlier neglect of infectious disease to their under-appreciation of the extent to which the problem of infectious disease is related to social factors and thus to questions of justice. We argue that a social causation of illness model - wellknown to sociologists of medicine, but incompletely understood by bioethicists - will improve future bioethical analysis of issues related to infectious disease. By emphasising the relationships between social and economic structures of inequality and health, the social causation model provides a richer approach to ethical issues associated with infectious disease than the more commonly used biomedical model.
\end{abstract}

Keywords: bioethics, infectious disease, social causation, poor countries

\section{Introduction}

After decades of neglect, bioethicists have begun to address the problem of infectious disease (Smith et al. 2004, Farmer and Campos 2004, Selgelid 2005, Francis et al. 2004, 2005). These preliminary forays into the ethical problems posed by infectious disease focus on several issues: (1) the severe consequences of infectious disease both in the past and, with the threat of avian flu and drug resistance looming, in the future; (2) the difficulty of implementing infectious disease control measures (such as quarantine) while preserving human rights; (3) the potential for infectious diseases to promote stigmatisation, panic and emotionally driven (policy) decision-making; and Publishing Ltd. Published by Blackwell Publishing Ltd., 9600 Garsington Road, Oxford OX4 2DQ, UK and 350 Main Street, Malden, MA 02148, USA 
(4) the justice issues raised by the relation between poverty and infectious disease. When compared to the topics of abortion, euthanasia, genetics, cloning and stem cell research, however, bioethical attention to infectious disease remains in its infancy.

We believe that the bioethical questions raised by infectious disease present the opportunity to develop a new approach to the resolution of the ethical quandaries, not just of communicable disease, but of medicine and the life sciences. Our approach, which draws from the insights afforded by social science, fits well with the interdisciplinary tradition of bioethics. In the following pages we show how the work of bioethics can be broadened and improved by taking medical sociology seriously.

\section{Bioethics and infectious disease}

With the important exception of HIV/AIDS, infectious disease, until very recently, for the most part got 'left out' of bioethics. Francis and her colleagues (2005) describe the extent to which infectious disease has been absent in standard bioethics texts, and our internet searches offer further evidence of the paucity of bioethics work in this area. A PubMed search of titles and abstracts (conducted in May 2004) ${ }^{1}$ for the terms 'ethics' and 'infectious disease' yielded a total of 195 citations; 'ethics' and 'AIDS' yielded 2,617; while 'ethics' and 'tuberculosis' yielded only 130, despite the fact that tuberculosis kills almost as many people as AIDS each year. 'Ethics' and 'genetics', in the meanwhile, yielded 8,400 citations; 'ethics' and 'euthanasia' yielded 8,288; 'ethics' and 'abortion' yielded 4,000. Although this kind of search is crude, the results are powerful and corroborate the notion that bioethics has paid relatively little attention to infectious disease.

As this citation search suggests, infectious diseases have not been entirely ignored by bioethicists. AIDS, for example, has received high profile attention in the bioethics literature. This coverage, however, has been limited in scope, extent and quality. Most early attention, which arose with the advent of AIDS, focused on doctor-patient relationship issues such as confidentiality, the ethics of mandatory testing and physicians' 'duty to treat' patients with AIDS (in spite of their fear of contagion). With regard to AIDS in developing countries, most of the attention has focused on international research ethics and the 'standards of care' debate in particular (i.e. the question of what should count as an ethically acceptable control arm in research involving human subjects) (see, for example, Schuklenk 2000). This latter debate has focused on controversial placebo-controlled studies (aimed at the prophylactic prevention of mother-to-child transmission of HIV in developing countries) that conflicted with the Declaration of Helsinki requirement that subjects in the control-arm should receive the 'best proven' or 'best current' treatment for their condition. Bioethics has otherwise paid surprisingly little attention to the overall justice of the healthcare situation in developing countries with 
regard to HIV and other infectious diseases, such as tuberculosis and malaria. An exception, however, is the growing body of bioethics literature addressing concerns that intellectual property rights in pharmaceuticals pose barriers of access to existing medicines and provide insufficient incentive for innovation in medicine (Schuklenk et al. 2002, Cohen et al. 2003, Sterckx 2004, Pogge 2005).

Increasing public attention to the problem of infectious disease - related to fears about bioterrorism, recent experience with SARS, the threat of a new flu pandemic, the growing danger of drug resistance, and the general increase in emerging infectious diseases during recent decades - suggests that bioethics can no longer afford to neglect this area. Indeed, there are several signs that bioethics is finally giving more attention to the topic of infectious disease, including the relatively new journal Developing World Bioethics (established in 2001), the recent appearance of a special edition of Bioethics on Ethical Issues in Infectious Disease (August 2005), and a growing interest in ethics and public health, illustrated by a number of books (Coughlin et al. 1998, Beauchamp and Steinbock 1999, Gostin 2002, Boylan 2004) and a special edition of Bioethics on Ethics and Public Health (November 2004). Since infectious diseases were primarily a problem for poor and developing nations during most of the second half of the $20^{\text {th }}$ century, it was easy for bioethicists, most of whom work in the first world, to relegate them as 'problems of the other' and to focus on issues of more obvious domestic concern (Selgelid 2005). Now, with infectious diseases again clearly threatening rich and poor countries alike, and with the requisite rethinking of international healthcare distribution and public health measures, infectious disease has found a place on the bioethics agenda.

The social sciences have much to offer bioethics as it turns its attention to infectious disease and associated questions of justice. First, the ethical issues relating to infectious disease require a broader engagement with social sciences - such as history, anthropology, sociology, political science and economics - than is typical for a philosophically-oriented bioethics (Farmer and Campos 2004). Appreciation of the (in)justice of the infectious disease situation in developing countries requires empirical understanding of the causes and consequences of infectious diseases, an understanding that the social sciences are prepared to offer (Selgelid 2004, 2005). Second, we believe that the capacity for dealing with the bioethical problems of infectious disease will be enhanced by a shift away from the biomedical model toward a sociological model of disease causation that shows how the structures of society are related to health and healthcare outcomes.

\section{Justice and the empirical facts}

HIV/AIDS, tuberculosis and malaria combine to kill roughly six million people each year, primarily in developing countries. Of the approximately 40 
million people currently infected with HIV, two-thirds live in Africa and 95 per cent reside in developing countries. While some may be tempted to think that AIDS' heavy toll in impoverished countries is somehow the fault of the individuals affected (a product of promiscuous sexual practices or reckless drug use, for example) or a matter of misfortune rather than injustice, the social scientific study of AIDS reveals that things are not so simple (see Webb 1997, Marias 2000, Whiteside and Sunter 2000, Barnett and Whiteside 2002, Farmer 1999, Farmer and Campos 2004, Farmer 2003, Hunter 2003). AIDS takes a heavy toll on the African poor because: (1) they lack good nutrition, which weakens their immune systems and increases chances of infection; (2) they lack options with regard to ways of making a living (and so women are pressured into prostitution and men must work in mines remote from their families and marital partners); (3) women are disempowered and have little control in sexual practices with male partners; (4) young women are often sexually abused by older males; (5) education, and thus public understanding of diseases like AIDS, is limited; and (6) life is generally so hard that fatalistic behaviour is common - and thus even those who are aware of the risk of AIDS are often undaunted, as a disease that might kill one 10 years from now is not any more frightening than risks that one faces on a daily basis.

While these factors increase the risk of infection with HIV, matters are made worse because of a vicious cycle of poverty and disease: the poor are unable to afford expensive AIDS medications; their weakened immune systems allow AIDS to progress with greater speed and severity; and their illness and death further compound the poverty of their families and contribute to the poverty of their communities. The poverty and disempowerment driving this cycle of disease in Africa is a product of a long history involving slavery, colonialism, racism, exploitation, and (in the case of South Africa, home to more HIV-infected individuals than any other country in the world) apartheid (Barnett and Whiteside 2002, Hunter 2003).

Like the causes of HIV/AIDS in Africa, the likely consequences of the disease - for developing and developed countries alike - are also extremely complex and relevant to justice. HIV threatens entire societies with collapse, and the current situation in sub-Saharan Africa may follow in parts of Asia and the former Soviet Union. Instability in affected regions, meanwhile, has serious health, economic and security implications for both wealthy and poor nations (National Intelligence Council 2000).

In less dramatic fashion but with equal importance, we must consider the non-epidemic prevalence of infectious disease in poor countries. Indeed, the illness burden of poor populations in developing countries is routinely defined in terms of all diseases, not just those that are epidemic (Murray and Lopez 1996). As a case in point we might consider the health conditions found in rural villages in Nepal (Subedi et al. 2000). The most prevalent health problems found in these villages include gastrointestinal, respiratory and genitourinary infections, and pelvic inflammatory disease. The life expectancy 
in Nepal is 58 years and infant mortality ranges from 100-115 per thousand - compared to 7-9 in the United States.

High rates of infection in the developing world are directly attributable to contextual factors such as contaminated water supplies, non-existent sanitary systems and the absence of modern healthcare resources. The typical villager in Nepal occupies a single-story two-room hut constructed of mud and brick with a dirt floor and an animal shed attached. Human-animal interaction is close. The rooms are crowded with multiple generations. There is no ventilation system and an open hearth is used for cooking and heat. The house is not insulated. There is no indoor lavatory and family members often use the latrine without wearing shoes. The water supply is routinely contaminated with faeces. The family diet lacks protein and micronutrients. There is no modern healthcare available except by travelling on foot for days. Infectious disease is a normal experience in such a setting but, as medical sociologists have long known, the high rates of disease are not attributable to individual health behaviours. Rather, they reflect the poverty of the socio-economicbiological environment (Subedi et al. 2000).

As bioethicists begin their systematic analysis of the ethical dimensions of infectious disease and health problems in developing countries, they will find the insights of the social sciences to be invaluable. In particular, the sociological explanation for illness will provide a richer and more appropriate framework for the study of these bioethical issues than the widely used (or presumed) biomedical model.

Because it does not capture the broader causes and consequences of health and medical care, the biomedical model of health and illness is of limited value in explaining the origin, treatment and prevention of infectious disease. In fact, the limited attention given infectious disease by bioethics may well be the result of the absence of an adequate understanding of the scope of the problem and, therefore, its ethical dimensions (Fox 1989). The link between poverty and infectious disease, for example, cannot be sufficiently explained by biomedicine. Understanding this link requires consideration of the origins of poverty and the poverty-related social mechanisms that increase exposure and vulnerability to infectious diseases. Those who adopt the broader, sociological perspective see issues of social justice that are otherwise not apparent. Indeed, as Fox argues, bioethics as a discipline has been disinclined to grapple with the relationship between poverty and illness because poverty is regarded as a social rather than an ethical issue.

\section{Accounting for infectious disease}

Critiques of the biomedical model are familiar (see, for example, Gordon 1988, Fee and Krieger 1993, Link and Phelan 1995). Gordon (1988) identifies two core presumptions of modern biomedicine that we regard as most germane to our argument. Biomedicine assumes: (1) that illness is located in 
the individual and (2) that nature is separate from the social order. The presumption that illness is located in the individual has, in fact, been linked to failures to adequately address public health policy (Fee and Krieger 1993, Porter et al. 1999, Smith et al. 2004). Porter, Ogden and Pronyk (1999) suggest that the emphasis on illness as an individual experience leads policy makers to develop 'micro' policies that address specific diseases at an individual, clinical level. They also argue that these policies are ineffective for dealing with the true character of infectious diseases such as AIDS or multi-drug-resistant tuberculosis (MDRTB).

Bioethics typically focuses on clinical relationships, reproducing the individualistic presumption of biomedicine that is focused on specific patients whose disease or disorder is explained by personal conditions (genetics, lifestyle, choices, etc.). Individualism as a moral value is a cardinal principle of bioethical thinking; this is partly illustrated by the high priority so often placed on 'autonomy' in bioethics discourse (Wolpe 1998, Francis et al. 2005). As a result, when ethical issues related to infectious disease and disease in developing countries are addressed, there is still an attempt to separate biomedical research from the 'unjust conditions where the research is conducted' (CIOMS 2002). In effect, this reinforces the notion that nature and society are two distinct spheres. Policy analysts, researchers, and lately, even some ethicists, have called for a disease model that takes into account the real conditions of people's lives and the social and material bases of disease transmission (Smith et al. 2004, Porter et al. 1999, Fee and Krieger 1993).

Most public health models are attentive to the social contexts of illness, and yet they are not sufficient for understanding disease causation and its implications for bioethics. While public health models recognise the environment as a source of disease (risk), the 'socio-medical' approach they offer is based on epidemiological studies that associate disease with specific segments of the population or behaviours. The focus remains on individual risk, single vectors, and policies aimed at controlling a specific source of illness (Porter et al. 1999, Potvin et al. 2005). Public health models do raise bioethical issues about the relationship between contagion and personal liberty, but they remain focused on individuals and the population-based strategies aimed at reducing individual risk. They are not adequate for explaining how macro-structural conditions affect general exposure to infectious disease (i.e. create risk). Public-health-inspired community interventions often lead to significant health improvements, but they do not dissolve class differences in morbidity and mortality (relative risk).

\section{The sociological explanation for illness}

Because the sociological model of illness does a better job of explaining the origins of infectious disease and the capacity to respond to illness, it makes the ethical issues related to infectious disease more apparent. Epidemiological 
studies often point to differences in mortality and morbidity that are linked to social factors such as socio-economic status, race/ethnicity and gender. Lacking a theoretical framework, however, these studies are of limited use (Potvin et al. 2005). We need a theory that links social conditions and health/infectious disease at the structural level rather than at an individual - or even aggregated individual - level (Farmer 1999, 2003, Farmer and Campos 2004, Robert and Smith 2004). Medical sociologists have developed an account of illness that offers a structural explanation of disease. When we recognise that social structure actually causes illness (creates risk), we are able to see the otherwise invisible connection between illness and society. The fact that tremendous differences in material resources between rich and poor countries are mirrored by equally large disparities in mortality and morbidity suggests that material conditions are central to explanations of illness. Awareness of this is crucial to the development of bioethical principles.

The sociological explanation for illness starts not with individual biologic capacity but with observations about the structured risk of biologic disruption. For example, the sociological explanation for why poor people have higher mortality and morbidity points to the ways a shared social status affects exposure to health risks and the ability to deal with those risks. Most physicians are aware that rates of illness and mortality vary by socioeconomic status, ethnicity and gender. The socio-medical (public health) interpretation of these differences is that they are related to differences in genetic characteristics and health behaviours such as diet, exercise, cigarette smoking and other lifestyle choices that vary by class, ethnicity and gender. Factors such as socioeconomic status are correlated with mortality and morbidity simply because people's lifestyles differ by socioeconomic levels. This is a useful first step, but it is a limited explanation of the relationship between social structure and illness because it does not recognise that social status differences in and of themselves cause disease.

The sociological perspective views socioeconomic status differences as considerably more than mere variations in lifestyle. Socioeconomic status reflects broad access to resources such as money, knowledge, prestige, power and beneficial social connections that enable individuals to avoid risks (including health risks) and to deal with adversity when it occurs (Phelan et al. 2004, Link and Phelan 1995). And, as risk factors change, persons in better socioeconomic positions are better able to adjust to changing conditions. When the association between smoking and lung cancer became known, for example, reductions in smoking were more immediate and significant in upper socioeconomic strata. Hence, those who were already in better possession of resources were able to take advantage of the new information to protect their health. Public health models are partial reflections of this observation. At any given historical moment, the social, economic and physical environmental conditions that more directly cause an illness may be modified to reduce the incidence of new cases. It is however notable that public health 
programmes, while they have reduced mortality and morbidity for many diseases, have not eliminated the 'social gradient' related to mortality and morbidity. Socio-economically-disadvantaged groups still have higher rates of morbidity and mortality despite public health programmes.

The sociological explanation for illness, then, emphasises the effects of socioeconomic differences in resource possession as a causal factor in health and illness. Its application in very poor countries as an explanation of health status relative to richer countries is thus evident. Health statistics at the national level show the gross differences in mortality and morbidity between rich and poor countries. Poor countries face different levels of risk and have different access to health-protective resources than rich nations in part because they are embedded in a political-economic world-system. This perspective places political-economic critiques of global resource distributions, and criticism based on the higher and qualitatively different disease burdens in poor countries, within a common framework of international and internal socio-economic structure. Wilkinson $(1992,1994)$ and Kennedy et al. (1996) have shown that income inequality across countries affects relative mortality and morbidity.

But we cannot stop our analysis at the level of inter-national differences. The explanation applies within countries as well. Income inequality directly affects access to personal resources including education, housing and nutrition - factors that affect exposure to health risks. In addition, the social distribution of resources includes the distribution of infrastructure resources such as safe drinking water, electricity, schools, healthcare and health providers, and economic opportunity. Each of these factors has been identified previously as a factor related to individual and population health. What the sociological explanation provides is an underlying connection based on the idea that these resources are allocated unevenly across and within societies based on stratification systems. Indeed, Link and Phelan (1995) call social conditions 'fundamental' causes of illness because, even if a disease-specific causal mechanism is altered (say by improving the quality of the food supply to eliminate nutrition-related disorders), the social gradient that was associated with risk of nutrition-related disorders will remain and will be associated with other illness via other mechanisms of exposure and vulnerability. Social causes of mortality and morbidity are fundamental because they influence multiple-disease outcomes and affect disease outcomes through a number of risk factors. Structural inequalities persist over time, and they involve access to resources that can be used to avoid risk or minimise the consequences of disease once it has occurred (Phelan et al. 2004).

The biomedical remedy for exposure to cholera in drinking water is to change the source of drinking water. Public health practitioners will agree with this remedy, but they will go further, pointing out that in order for an individual to drink untainted water, she will need a better income and the opportunity to obtain fresh water. But neither of these responses to cholera infection will eliminate the continued threat of infectious disease unless it is recognised that exposure and vulnerability to illness are related to social 
resource differences. It is clear (perhaps clearest in developing countries) that access to income and water is also related to the social distribution of resources and enduring differences in access to those resources based on social status. Incorporating this level of understanding of disease causation makes it easier to think about the bioethical matters entailed and the kinds of measures required to improve the status quo from an ethical perspective.

\section{Application of the model for a bioethics of infectious disease}

In very poor developing countries the normal fabric of daily life exposes individuals to many sources of infectious and other forms of illness. As in our description of life in Nepal, a poor farmer may live in an overcrowded, unventilated house with farm animals, no electricity or fresh water, eating tainted, nutrition-deficient food, using unsanitary toilet facilities. Modern healthcare will be both beyond his means and geographically distant. Moreover, the farmer will not understand how his life chances are affected by these conditions and, even if he did, there would be almost no changes that the farmer could make to improve any of these conditions. The sociological model of illness causation is helpful in understanding the aetiology and pathology of illness in this setting because it allows one to incorporate these daily conditions, borne of social structure and economic conditions, into an illness-causation model. An ethical- or justice-oriented health intervention would clearly need to deal with the impoverished material and social position of the farmer - an outcome not apparent using a biomedical model of illness.

Our sociological model allows us to specify areas in which bioethical principles need to be developed, especially regarding infectious disease in very poor countries. A bioethics derived from our model will focus on distributive justice and benefits measured at the population level (Bhutta 2002, Macklin 2001, Laurell and Arellano 2000, Kidanemariam 1995). In sociological models of illness, illness is a normal consequence of the organisation of social resources. This means that bioethical principles must account for the role that social organisation plays in determining health status, including the important but rarely acknowledged role of political-economic arrangements.

Two useful principles follow from our analysis. The first is that risks, benefits, and equity must be defined in terms of the international, national and local contexts and not just in terms of individual health. The sociological model makes it evident that health conditions originate in socio-economic conditions that need to be 'treated' to have an impact on the health status of individuals. Related to this first principle is a second: the need for a less restricted conception of the distribution of benefits that can account for the poverty of national and local healthcare systems as a function of social structure. At its core, the value of a sociological explanation of illness for bioethics lies in its implications for addressing the problem of justice. '[I]f we do not understand the broader social factors that are responsible for generating or exacerbating the health 
needs of developing world populations, we are unlikely to attend to the root causes of a community's health problems' (London 2005: 28).

\section{Conclusion}

We are convinced that a bioethics of infectious disease will benefit from adopting a sociological explanation of illness. Infectious diseases warrant more attention from bioethics because their consequences are so severe, because they raise difficult ethical/philosophical questions of their own, and because they are intertwined with issues of justice. As bioethicists begin sustained analysis of the problems posed by infectious disease, it is important that they recognise the limitations of a biomedical model of disease causation. A sociological model of disease causation recognises infectious disease as an issue of justice (and thus bioethics) and allows the formulation of bioethics principles appropriate to the contexts in which infectious diseases thrive.

Will bioethics embrace the topic of infectious disease as one of its core topics? While we celebrate the recent attention given to infectious disease by bioethicists, we are aware that obstacles to a thorough-going bioethics of infectious disease remain. Some scholars argue that bioethics suffers from a low level of rigour because bioethics discourse requires expertise in both ethics/philosophy and biomedical science. This difficulty is compounded in the context of infectious disease where rigorous discourse also requires an in-depth understanding of social science (Selgelid 2005). It remains to be seen whether or not bioethics educational institutions - so heavily dominated by philosophy and first-world universities - are up to the task of incorporating social sciences and developing world perspectives more deeply into their curricula.

Address for correspondence: Mark Tausig, Department of Sociology, University of Akron, Olin Hall 247, Akron, OH 44325-1905 USA e-mail:mtausig@uakron.edu

\section{Note}

1 This search was done by our colleague, Kathleen Montgomery.

\section{References}

Barnett, T. and Whiteside, A. (2002) AIDS in the Twenty-first Century: Disease and Globalisation. New York: Palgrave Macmillan.

Beauchamp, D.E. and Steinbock, B. (1999) New Ethics for the Public's Health. New York: Oxford University Press. 
Bhutta, Z.A. (2002) Ethics in international health research: a perspective from the developing world, Bulletin of the World Health Organization, 80, 114-20.

Boylan, M. (ed.) (2004) Public Health Policy and Ethics. Kluwer: Dordrecht.

Central Intelligence Agency (2003) Our Darker Bioweapons Future. Available at www.cia.org. [Accessed 4 November 2005].

CIOMS (Council for International Organizations of Medical Sciences) (2002) International Ethical Guidelines for Biomedical Research Involving Human Subjects. Geneva: CIOMS.

Cohen, C.J. and Illingworth P. (2003) The dilemma of intellectual property rights for pharmaceuticals: the tension between ensuring access of the poor to medicines and committing to international agreements, Developing World Bioethics, 3, 1, 27-48.

Coughlin, S.S., Soskolne, C.L. and Goodman, K.W. (eds) (1998) Case Studies in Public Health Ethics. Washington D.C.: American Public Health Association.

Farmer, P. (1999) Infections and Inequalities: the Modern Plagues. Berkeley, CA: University of California Press.

Farmer, P. (2003) Pathologies of Power: Health, Human Rights, and the New War on the Poor. Berkeley, CA: University of California Press.

Farmer, P. and Gastineau Campos, N. (2004) Rethinking medical ethics: a view from below, Developing World Bioethics, 4, 1, 17-41.

Fee, E. and Krieger, N. (1993) Understanding AIDS: historical interpretations and the limits of biomedical individualism, American Journal of Public Health, 83, 10, 1477-86.

Fox, R.C. (1989) The Sociology of Medicine. Englewood Cliffs, NJ: Prentice-Hall.

Francis, L.P., Battin, M.P., Botkin, J., Jacobson, J. and Smith, C. (2004) Research ethics and infectious disease: the moral significance of communicability. World Congress of the International Association of Bioethics, Sydney.

Francis, L.P., Battin, M.P., Botkin, J., Jacobson, J. and Smith, C. (2005) How infectious diseases got left out - and what this omission might have meant for bioethics, Bioethics, 19, 4.

Gordon, D. (1988) Tenacious assumptions in western medicine. In Lock, M. and Gordon, D. (eds). Biomedicine Examined. The Netherlands: Kluwer Academic Publishers.

Gostin, L. (ed.) (2002) Public Health Law and Ethics. Berkeley, CA: University of California Press.

Hunter, S. (2003) Black Death: AIDS in Africa. New York: Palgrave Macmillan.

Kennedy, B., Kawachi, I. and Prothrow-Stith, D. (1996) Income distribution and mortality: cross-sectional ecological study of the Robin Hood index in the United States, British Medical Journal, 312, 1004-7.

Kidanemariam, A. (1995) Health and development in the third world: the political economy of infant mortality in Brazil. In Gallagher, E.B. and Subedi, J. (eds) Global Perspectives on Health Care. Englewood Cliffs, NJ: Prentice Hall.

Laurell, A.C. and Arellano, O.L. (2000) Market commodities and poor relief: the World Bank proposal for health. In Navarro, V. (ed.) The Political Economy of Social Inequalities: Consequences for Health and Quality of Life. Amityville, NY: Baywood Publishing.

Link, B.G. and Phelan, J.C. (1995) Social conditions as fundamental causes of disease, Journal of Health and Social Behavior (Special issue), 80-94.

London, A.J. (2005) Justice and the human development approach to international research, Hastings Center Report, 35, 24-37. 
Macklin, R. (2001) After Helsinki: unresolved issues in international research, Kennedy Institute of Ethics Journal, 11, 17-36.

Marias, H. (2000) To the Edge: AIDS Review 2000. Pretoria: University of Pretoria, Centre for the Study of AIDS.

Murray, C.J.L. and Lopez, A.D. (eds) (1996) The Global Burden of Disease: a Comprehensive Assessment of Mortality and Disability from Diseases, Injuries and Risk Factors in 1990 and Projected to 2020. Cambridge, MA: Harvard School of Public Health, Harvard University Press on behalf of The World Health Organization and The World Bank.

National Intelligence Council (2000) The global infectious disease threat and its implications for the United States. Available at http://www.odci.gov/nic/PDF_GIF_ otherprod/infectiousdisease/infectiousdiseases.pdf. [Accessed 10 May 2005.]

Phelan, J.C., Link, B.G., Diez-Roux, A., Kawachi, I. and Levin, B. (2004) 'Fundamental causes' of social inequalities in mortality: test of the theory, Journal of Health and Social Behavior, 45, 265-85.

Pogge, T.W. (2005) Human rights and global health: a research program, Metaphilosophy, 36, 1/2, 182-209.

Porter, J., Ogden, J. and Pronyk, P. (1999) Infectious disease policy: towards the production of health, Health Policy and Planning, 14, 4, 322-8.

Potvin, L., Gendron, S., Bilodeau, A. and Chabot, P. (2005) Integrating social theory into public health practice, American Journal of Public Health, 95, 591-5.

Robert, J.S. and Smith, A. (2004) Toxic ethics: environmental genomics and the health of populations, Bioethics, 18, 6, 493-514.

Schuklenk, U. (2000) Protecting the vulnerable: testing times for clinical research ethics, Social Science and Medicine, 51, 969-77.

Schuklenk, U. and Ashcroft, R.E. (2002) Affordable access to essential medication in developing countries: conflicts between ethical and economic imperatives, Journal of Medicine and Philosophy, 27, 2, 179-95.

Selgelid, M.J. (2004) Ethics, economics and AIDS in Africa, Developing World Bioethics, 4, 1, 96-105.

Selgelid, M.J. (2005) Ethics and infectious disease, Bioethics, 19, 3, $272-89$.

Smith, C.B., Battin, M.P., Jacobson, J.A., Francis, L.P., Botkin, J.B., Asplund, E.P., Domek, G.J. and Hawkins, B. (2004) Are there characteristics of infectious disease that raise special ethical issues? Developing World Bioethics, 4, 1, 1-16.

Sterckx, S. (2004) Patents and access to drugs in developing countries: an ethical analysis, Developing World Bioethics, 4, 1, 58-75.

Subedi, J., Subedi, S., Sidky, H., Singh, R., Blangero, J. and Williams-Blangero, S. (2000) Health and health care in Jiri, Contibutions to Nepalese studies; the Jirel Issue, January, 97-104.

Webb, D. (1997) HIV and AIDS in Africa. London: Pluto Press.

Whiteside, A. and Sunter, C. (2000) AIDS: The Challenge for South Africa. Cape Town: Human and Rousseau.

Wilkinson, R.G. (1992) Income distribution and life expectancy, British Medical Journal, 304, 165-8.

Wilkinson, R.G. (1994) The epidemiological transition: from material scarcity to social disadvantage? Daedalus, 123, 61-77.

Wolpe, P. (1998) The triumph of autonomy in American bioethics: a sociological view. In De Vries, R. and Subedi, J. (eds) Bioethics and Society: Constructing the Ethical Enterprise. Upper Saddle River, NJ: Prentice Hall. 